\title{
Effect of shod walking on plantar pressure with varying uphill gradients
}

\author{
Suranjana Sen ${ }^{1}$, Debojyoti Bhattacharyya ${ }^{2}$, Subhojit Chaterjee ${ }^{3}$, Bhuvnesh Kumar ${ }^{4}$, \\ Madhusudan Pal ${ }^{5}$ \\ ${ }^{1,3}$ Senior Research Fellow, ${ }^{2}$ Scientist -D, ${ }^{4}$ Director, Defence Institute of Physiology and Allied Sciences, Lucknow \\ Road, Timarpur, Delhi-110054, India, ${ }^{5}$ Scientist-F and Additional Director, Head, Department of Ergonomics, Defence \\ Institute of Physiology and Allied Sciences, Lucknow Road, Timarpur, Delhi-110054, India
}

Background: Uphill walking is biomechanically stressful. Changes in plantar pressure, is one of the important predictors of this stress and increased risk of foot injuries. It has been reported that civilians as well as different occupational workers have to walk over uphill gradient with footwear which may cause changes in plantar pressure. Till date published data on plantar pressure is not available of Indian population during shod walking with uphill gradients. Aims and Objective: The present study was aimed to generation of data base on plantar pressure and find out the effect of shod walking (wearing occupational boot) on plantar pressure at different uphill gradients. Materials and Methods: Twenty healthy male participated in this study. Plantar pressure was recorded using the pressure measurement system during walking at $4 \mathrm{~km} / \mathrm{hr}$ speed on treadmill at level and different uphill gradients. Results: It was observed that the PP at all the five regions of both right and left foot (Forefoot, Mid-foot, Medial, Lateral, Heel and Overall) increased gradually along with the increase in gradients. There was significant increase of $8.94 \%, 9.93 \%, 18.22 \%, 16.06 \%, 10.27 \%$, $12.92 \%$ respectively at left forefoot, mid-foot, heel, medial, lateral and overall regions at $10 \%$ gradient compared to level walking. Similarly, in right foot the increase was observed $8.20 \%, 10.82 \%, 14.28 \%, 13.75 \%, 8.27 \%, 10.88 \%$ in respective foot regions compared to level walking. Conclusion: Observations of the present study stated that with increasing gradient plantar pressure at various foot regions increased in both feet in comparison to level walking, maximum plantar pressure observed in heel region in both feet in comparison to other studied regions. This data will be considered as normal planter pressure value of adults at level and uphill gradients shod walking and may be utilized for prognosis of foot disorders and efficacy of treatment modalities of population comparable with studied individuals (for similar age, height and weight).

Key words: Plantar pressure; Foot regions; Uphill walking; Foot injury risk

\section{Access this article online}

Website:

http://nepjol.info/index.php/AJMS DOI: 10.3126/ajms.v11i6.29902

E-ISSN: 2091-0576

P-ISSN: 2467-9100

Copyright (c) 2020 Asian Journal of Medical Sciences

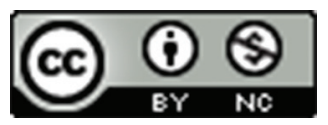

This work is licensed under a Creative Commons Attribution-NonCommercial 4.0 International License.

\section{INTRODUCTION}

During walking interactive forces are transferred between the human body and ground. Measurement of these ground contact forces in an unit of foot area can be used to assess the external load to which human body is subjected to expose in different situations. This form of mechanical pressure is termed as plantar pressure (PP). According to Mueller, pressure is a form of mechanical stress, which is equal to the magnitude of the perpendicular force to a specific surface area. Information derived from such pressure measures is important for diagnosing lower limb problems, footwear design, sport biomechanics, injury prevention and other applications. ${ }^{1}$ Various anthropometric and kinematic factors have been identified which affect the PP. Age related differences have been described between children and adults. ${ }^{2}$ There are a lot of differences between adult and elderly population. Ageing is associated with significant changes in foot characteristics which contribute to altered plantar loading patterns during gait. Older people exhibit flatter feet, reduced range of motion, tactile sensation and strength, and a higher prevalence of foot deformities. ${ }^{3}$ 
Gender also affects the pattern of plantar loading as Queen et al. found that PP value is significantly higher under the forefoot region of the male subjects during gait. ${ }^{4}$ Foot shape is another important factor which may cause the plantar loading variation. Different foot structures like cavus or planus foot deliberately reveals different pressure distribution patterns. Higher amount of pressure has been found in mid-foot region of planus foot and central forefoot region in cavus foot. ${ }^{5}$ Gait velocity can also change the plantar loading pattern. There was a linear increase in heel and medial forefoot with increasing speed whereas in mid-foot and lateral region it was decreased with speed. ${ }^{6}$

There have been ample advancements in PP measurement over the recent times in understanding the pressure generated by the feet during human locomotion, both qualitatively and quantitatively. Information from these measurements have provided essential support in the assessment of various foot pathologies, including rheumatoid arthritis, ${ }^{7}$ Parkinson's disease, ${ }^{8}$ and diabetes, ${ }^{9}$ and peripheral neuropathy. ${ }^{10}$ Accordingly clinicians used to suggest the appropriate insole/ footwear to alleviate the pressure problems. Measurement of PP has immense importance in the domain of sports biomechanics for predicting the risk of slip and fall; bone, ligament, tissue injury/fracture; efficacy of the footwear etc. ${ }^{1}$ One of the earliest applications of PP was the evaluation of footwear. Lavery et al. ${ }^{11}$ in 1997 determined the effectiveness of therapeutic and athletic shoes with and without viscoelastic insoles using the mean peak plantar pressure as the evaluation parameter. Mueller ${ }^{12}$ applied plantar pressure to the design of footwear for people without impairments (i.e., the civilian population). Furthermore, Praet and Louwerens ${ }^{13}$ and Queen et al. ${ }^{4}$ found that the most effective method for reducing the pressure beneath a neuropathic forefoot is using rocker bottom shoes and claimed the rocker would decrease pressure under the first and fifth ray (metatarsal head). Another research area of plantar pressure measurement is to design footwear to fulfill the occupational requirements. For example, shoes may need protective or traction properties in order to allow the individual to safely and effectively carry out a required task. One such occupation is mining, which requires workers to stand for long periods of time on sometimes uneven, wet or unstable surfaces. In a group of miners it was observed that increased incidents of foot pain was due to the mismatch of width of the existing shoes. ${ }^{14}$ Contact areas of foot, maximum force, maximum pressure and average pressure have influencing effect on PP. It was found in hikers that comparatively light weight shoes are more beneficial in terms of increased feelings of comfort and fit due to increase in the contact area and decrease in peak pressure. Thus, fatigue at foot and pelvic limbs were delayed. ${ }^{15}$ As discrete occupational group, soldiers are also highly mobile in their daily work schedule, which involves variety of maneuvers like normal walking, marching, running, jumping, jogging etc. These maneuvers can be the part of their regular training as well as a real time combat scenario. Moreover, these activities have to be carried out over a range of terrain conditions namely mountainous/ hilly, jungle, desert etc. Among these, mountain terrain is mostly characterized with hard rocks and uphill gradients. Vigorous movements in these terrains engross repetitive and frequent uphill walking which can be especially challenging for the individual. During their course of movements there is a high intensity kinetic interaction between foot and contact surfaces. The degree of changes depends on the physical property of the surface. These vigorous movements of soldiers over multiple terrains with elevations may lead to changes in plantar pressure in different foot regions. It can immensely contribute to strains and sprains in the legs, and they may experience muscle knots in their various lower limb muscles. In addition, high pressures may be felt at the plantar surface from ill-fitting footwear which may lead to pain sensation to the wearer. The physiological and biomechanical stress of uphill walking has been evaluated in normal civilian population by recording the changes in oxygen consumption and muscular activities. ${ }^{16,17}$ Scanty of studies have reported the biomechanical stress by recording the changes in PP during inclined gait by assessing the civilian population only. ${ }^{18-21}$ Considering the global scenario, only a very few studies have been reported regarding the biomechanical stress under various occupational condition. It was observed that 53000 valuable training days were lost and $\$ 16$ million compensation amount was levied per year due to musculoskeletal complaints among the US navy personnel. To find out the underlying root cause of this problem, kinetic recordings were conducted during walking, marching and running and it was suggested to bring about improvements in the forefoot cushioning of combat footwear. ${ }^{22-25}$ Trone et al. evaluated the biomechanical properties of available boots and provided recommendations for optimum biomechanical properties. ${ }^{24}$ In German army, the cushioning properties of army footwear have been identified as insufficient and related to a higher risk for injuries. ${ }^{26}$ Evaluating the effects of slope/gradient walk on the changes in plantar pressure at various foot regions, is relatively a growing field of research. A scanty of research attempts have been done till date. The present study was aimed to generation of data base on plantar pressure and find out the effect of shod walking (wearing occupational boot) on plantar pressure at different uphill gradients.

\section{MATERIALS AND METHODS}

\section{Participants}

Twenty $(n=20)$ physically fit Indian healthy male without any previous history of musculoskeletal disorders, fractures, disorders of the locomotors or vestibular systems 
etc, volunteered for the study. Their mean ( \pm SD) age, height and weight were $40.05( \pm 6.41)$ years, $168.95( \pm 6.80) \mathrm{cm}$ and $75.55( \pm 8.30) \mathrm{kg}$ respectively. Before the commencement of the experiments the participants were acquainted with the experimental design and their informed written consent were taken.

\section{Ethical clearance}

The study protocol was approved by the Institutional Ethics Committee on the use of the human as the experimental subjects and the experiment conforms to the principles outlined by the deceleration of Helsinki protocol, 1985.

\section{Experimental protocol}

A week prior to undertaking the experiments, the subjects routinely wore the boots provided for habituation during their duty hours. At first participants were habituated to walk on the motorized treadmill at various gradients in the laboratory. This attempt reduced the chances of slip and fall during the experiments. Participants fitted with foot scan insole (M/s Medilogic 5.8, Germany) as per their foot dimension (just beneath the skin of their own plantar surface of both feet) and the cables from each insole were connected to the data logger modem which was tightly fitted at the waist region using a waist belt. Each participant underwent on treadmill for six minutes at each gradient $(0 \%$, level), (5\% and $10 \%$ uphill) at $4 \mathrm{~km} / \mathrm{hr}$ walking speed. During experiment each participant wore regular combat boot (weight-1.5 kg). Plantar pressure was measured continuously for six minutes walking by using foot scan insole and whole six minutes' data was considered for processing and statistical analysis. All the experiments have been conducted in a controlled laboratory environment of $23-25{ }^{\circ} \mathrm{C}, 36-45 \%$ relative humidity and at the same time of the day (1030 h and $1300 \mathrm{~h})$.

\section{Parameter}

Plantar pressure $\left(\mathrm{N} / \mathrm{cm}^{2 *} \mathrm{~s}\right)$ in five different foot regions i.e. Forefoot, Mid-foot, Lateral, Medial and Heel and overall plantar pressure of foot.

\section{Statistical analysis}

Descriptive statistics in the form of mean and standard error of mean (SEM) of the raw data of different parameters were calculated. One-way repeated measure ANOVA was conducted to observe the significant effect of experimental independent variables i.e. changes in gradient $(0,5,10) \%$ on experimental dependent variables, i.e. Plantar pressure at different foot regions (forefoot, mid-foot, heel, medial, lateral, overall) followed by overall significance a pair-wise Bonferroni post Hoc test was conducted to find out the significance of PP changes for comparison between one pair of gradient. A correlation was conducted in predicting strength of relation between overall pressure and the pressure of specific region of foot separately across all gradients for individual foot. Application of partial correlation estimated an absolute correlation between overall pressure and a pressure of specific foot region while controlling the effects of other foot regions.

\section{RESULTS}

Changes in plantar pressure in both left and right foot were increased gradually during walking uphill gradients $(5 \%$, $10 \%$ in comparison to level. Forefoot, heel, mid-foot, medial, lateral, overall plantar pressures were increased (Table 1) Results of one way repeated measures ANOVA revealed that gradients caused significant changes in PP in left heel $\left[\mathrm{F}_{(2,36)}=18.28 ; \mathrm{P}<0.05\right]$, Forefoot $\left[\mathrm{F}_{(2,36)}=5.99\right.$; $\mathrm{P}<0.05]$, medial $\left[\mathrm{F}_{(2,36)}=30.29 ; \mathrm{P}<0.05\right]$, lateral $\left[\mathrm{F}_{(2,36)}=9.02 ; \mathrm{P}<0.05\right]$, and overall $\left[\mathrm{F}_{(1.26,22.67)}=29.46\right.$; $\mathrm{P}<0.05]$; and right heel $\left[\mathrm{F}_{(1.29,23.24)}=7.15 ; \mathrm{P}<0.05\right]$, forefoot $\left[\mathrm{F}_{(1.63,29.46)}=4.48 ; \mathrm{P}<0.05\right]$, medial $\left[\mathrm{F}_{(1.98,35.62)}=18.47\right.$; $\mathrm{P}<0.05]$, overall $\left[\mathrm{F}_{(2,36)}=31.17 ; \mathrm{P}<0.05\right]$ (Table 2). From pair wise comparison it was observed that in heel region plantar pressure was increased by $18.22 \%$ in left foot which was statistically significant $(\mathrm{P}=0.000)$ when compared to level. Similarly, right heel pressure was more affected by $10 \%$ gradient than left heel. In left medial region of foot there was an increase of $15.18 \%$ and $16.06 \%$ respectively in $5 \%$ and $10 \%$ and likewise in right medial region there was an increase of $11.84 \%$ and $13.75 \%$ which were found statistically significant when compared with level walking $(\mathrm{P}<0.05)$. On the contrary in forefoot and mid foot region of both feet, there was no significant change observed in PP. However, in left mid-foot region the percentage of increase in PP were observed $10.42 \%$ and $9.93 \%$ respectively at $5 \%$ and $10 \%$ gradient. The results also showed that overall plantar pressure was significantly increased by the effect of slope $(p<.001)$ in both feet. Pairwise comparison revealed significant maximum increase of $12.92 \%$ in overall $\mathrm{PP}$ while walking $0 \%$ to $10 \%$ gradient in left foot. Whereas in right foot significant increase of PP by $10.88 \%$ was only found in $10 \%$ gradient (Table 2 ). It can also be observed from the results that heel region in both feet were mostly affected by gradient comparing with other regions.

Correlations among the overall plantar pressure and pressures at different foot regions of both feet across all uphill gradients are presented in Table 3. The results of partial correlations revealed the entire strength categories viz. low, moderate and high ranging from 0.072 to 1.00 . In left foot, it was found that overall pressure significantly correlated with medial pressure at all gradients as well as level walking $(r=0.967$ at $0 \%, r=0.967$ at $5 \%$ and $r=0.975$ 


\begin{tabular}{|c|c|c|c|c|c|c|}
\hline \multirow[t]{2}{*}{ Foot Regions } & \multicolumn{3}{|c|}{ Gradient } & \multicolumn{3}{|c|}{$\%$ changes } \\
\hline & $0 \%$ & $5 \%$ & $10 \%$ & 0 Vs. 5 & 0 Vs. 10 & 5 Vs. 10 \\
\hline Left Forefoot & $4.72 \pm 0.05$ & $5.23 \pm 0.05$ & $5.18 \pm 0.05$ & $9.73 \uparrow$ & $8.94 \uparrow$ & $0.87 \downarrow$ \\
\hline Right forefoot & $5.13 \pm 0.05$ & $5.55 \pm 0.05$ & $5.59 \pm 0.05$ & $7.57 \uparrow$ & $8.20 \uparrow$ & $0.69 \uparrow$ \\
\hline Left mid-foot & $2.54 \pm 0.05$ & $2.83 \pm 0.05$ & $2.82 \pm 0.05$ & $10.42 \uparrow$ & $9.93 \uparrow$ & $0.55 \downarrow$ \\
\hline Right mid-foot & $2.61 \pm 0.05$ & $2.88 \pm 0.05$ & $2.93 \pm 0.05$ & $9.30 \uparrow$ & $10.82 \uparrow$ & $1.67 \uparrow$ \\
\hline Left lateral & $4.91 \pm 0.05$ & $5.27 \pm 0.05$ & $5.47 \pm 0.06$ & $6.95 \uparrow$ & $10.27 \uparrow$ & $3.56 \uparrow$ \\
\hline Right lateral & $5.04 \pm 0.05$ & $5.29 \pm 0.05$ & $5.50 \pm 0.06$ & $4.65 \uparrow$ & $8.27 \uparrow$ & $3.80 \uparrow$ \\
\hline Left medial & $4.03 \pm 0.04$ & $4.75 \pm 0.04$ & $4.80 \pm 0.04$ & $15.18 \uparrow$ & $16.06 \uparrow$ & $1.05 \uparrow$ \\
\hline Right medial & $4.35 \pm 0.04$ & $4.93 \pm 0.04$ & $5.04 \pm 0.04$ & $11.84 \uparrow$ & $13.75 \uparrow$ & $2.16 \uparrow$ \\
\hline Left Heel & $5.80 \pm 0.06$ & $6.59 \pm 0.06$ & $7.09 \pm 0.08$ & $11.94 \uparrow$ & $18.22 \uparrow$ & $7.13 \uparrow$ \\
\hline Right Heel & $5.90 \pm 0.05$ & $6.45 \pm 0.06$ & $6.89 \pm 0.07$ & $8.45 \uparrow$ & $14.28 \uparrow$ & $6.36 \uparrow$ \\
\hline Left overall & $4.46 \pm 0.04$ & $5.00 \pm 0.04$ & $5.12 \pm 0.05$ & $10.85 \uparrow$ & $12.92 \uparrow$ & $2.32 \uparrow$ \\
\hline Right overall & $4.59 \pm 0.05$ & $5.10 \pm 0.05$ & $5.15 \pm 0.05$ & $10.03 \uparrow$ & $10.88 \uparrow$ & $0.94 \uparrow$ \\
\hline
\end{tabular}

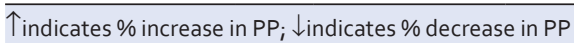

\begin{tabular}{|c|c|c|c|c|c|c|c|}
\hline & & \multirow[t]{2}{*}{ F value } & \multirow[t]{2}{*}{$P$ value } & \multirow[t]{2}{*}{ df } & \multicolumn{3}{|c|}{ Pair-wise comparison } \\
\hline & & & & & 0 vs $5 \%$ & 0 vs $10 \%$ & 5 vs $10 \%$ \\
\hline \multirow[t]{6}{*}{ LEFT FOOT } & Overall & 29.46 & $0.000^{*}$ & $(1.26,22.67)$ & $0.000^{*}$ & $0.000^{*}$ & $0.002^{*}$ \\
\hline & Heel & 18.28 & $0.000^{*}$ & $(2,36)$ & $0.000^{*}$ & $0.000^{*}$ & 0.525 \\
\hline & Forefoot & 5.99 & $0.006^{*}$ & $(2,36)$ & 0.08 & $0.008^{*}$ & 1.00 \\
\hline & Mid-foot & 2.69 & 0.10 & $(1.39,24.97)$ & 0.429 & $0.007^{*}$ & 1.00 \\
\hline & Medial & 30.29 & $0.000^{*}$ & $(2,36)$ & $0.000^{*}$ & $0.000^{*}$ & 1.00 \\
\hline & Lateral & 9.02 & $0.001^{*}$ & $(2,36)$ & $0.01^{*}$ & $0.000^{*}$ & 1.00 \\
\hline \multirow[t]{6}{*}{ RIGHT FOOT } & Overall & 31.17 & $0.000^{*}$ & $(2,36)$ & 0.24 & $0.000^{*}$ & $0.000^{*}$ \\
\hline & Heel & 7.15 & $0.009^{*}$ & $(1.29,23.24)$ & 0.407 & $0.000^{*}$ & 0.20 \\
\hline & Forefoot & 4.48 & $0.03^{*}$ & $(1.63,29.46)$ & 0.407 & $0.002^{*}$ & 0.92 \\
\hline & Mid-foot & 1.30 & 0.28 & $(1.32,23.82)$ & 0.8 & $0.05^{\star}$ & 1.000 \\
\hline & Medial & 18.47 & $0.000^{*}$ & $(1.98,35.62)$ & $0.05^{*}$ & $0.000^{*}$ & $0.009^{*}$ \\
\hline & Lateral & 3.2 & 0.08 & $(1.28,23.12)$ & 0.93 & $0.002^{*}$ & 0.73 \\
\hline
\end{tabular}

\begin{tabular}{l}
$\begin{array}{l}\text { Table 3: Partial correlation between overall pressure and pressure at other regions of foot across all } \\
\text { gradients in both feet }\end{array}$ \\
\cline { 7 - 8 }
\end{tabular}

at $10 \%$ gradient). Whereas, a high and significant correlation was observed between overall pressure and lateral pressure in level $(\mathrm{r}=0.965)$ and $5 \%$ gradients $(\mathrm{r}=0.967)$. In $10 \%$ gradient overall pressure was significantly correlated with mid-foot $(r=-0.916)$. In right foot, overall pressure was strongly correlated with forefoot pressure at 5\% gradient only $(\mathrm{r}=-0.83)$. In $10 \%$ gradient, heel and lateral pressure were also strongly correlated with overall pressure $(\mathrm{r}=1.000$, $\mathrm{r}=0.74)$. Medial plantar pressure was also correlated with overall pressure but that is weak $(r=0.431)$. 


\section{DISCUSSION}

The present study was aimed to generation of data base on plantar pressure and find out the effect of shod walking (wearing occupational boot) on plantar pressure at different uphill gradients on treadmill. Observations of the present study are as follows- with the increase in gradient plantar pressure at various foot regions increased gradually in both feet in comparison to level walking, and maximum plantar pressure observed in heel region in both feet in comparison to other studied regions. It was observed that the PP increased in all regions of the foot with the increasing gradients in both feet. These observations are contrasted by the findings of the previous studies. ${ }^{18,19}$ Ho et al. ${ }^{18}$ conducted experiments with the variation of gradients $(0,5,10,15 \%)$ and speed $(5.4,7.5,9 \mathrm{~km} / \mathrm{h})$ to observe the changes in PP where it was found that heel peak pressure reduced by $27 \%$ from $0 \%$ to $15 \%$ inclination. On the contrary, the PP increased by $33 \%$ at this region with the increase of speed from $5.4 \mathrm{~km} / \mathrm{h}$ to $9 \mathrm{~km} / \mathrm{h}$ and finally interpreted that speed is mostly contributing in the process of changes in PP compared to changes in gradient. Almost similar observation was found by Grampp et al. ${ }^{19}$ following a protocol with manipulation of only gradient factor i.e. uphill and downhill $(-15 \%,-8.5 \%$, Level, 8.5\%, 15\%) and concluded that with the increasing gradient the plantar loading increased in the forefoot region and decreased in heel region. Thus, these discrepancies in the observations between the present study and the previous studies (as discussed formerly) may be explained by the adaptation to the individual's gait pattern to increasing gradient at a constant speed (a moderate walking speed) for the present study and increasing speed (either running or jogging) at a constant gradient for the study by Ho et al. Hence, it can be postulated in majority of the cases PP may be influenced by the condition of speed of mobility i.e. walking, jogging and running which is irrespective of increase in gradients. They reported a decrease in the duration of the stance phase with increased walking speed. As speed increased, step length in both young adults and older adults, and stride length in older adults, also increased, corroborating the findings of a previous study. ${ }^{27}$ The effects of gait speed on the minimum and maximum values of joint angles have also been reported, including increases in hip flexion, hip extension, knee flexion, and ankle plantar flexion angles with higher speeds. ${ }^{28}$ Although for present study, it was observed that the pressure increased proportionately with the increasing gradient while maintaining a constant walking speed. Besides the influence of variations in speed and gradient there are other major methodological independent factors like variation in duration of the treadmill walking (present study for 6 minutes walking, Ho et al. for 30 seconds, ${ }^{18}$ Grampp et al. for 2 minutes; ${ }^{19}$ and analysis of recorded data either for entire experiment duration or fraction of the data from entire duration (present study presented data of entire experiment duration, Ho et al. presented 30 seconds data, ${ }^{18}$ Grampp et al. presented last 20 seconds data: ${ }^{19}$ data presented from single foot or both feet (for present study data presented separately for both feet, Ho et al. not mentioned, ${ }^{18}$ Grampp et al. presented only right foot data. ${ }^{19}$ Type and morphology of footwear also played vital role in distribution of PP at various regions of the foot. Dong et al. found that increasing heel height and inclination resulted in increasing PP in mid-foot and decrease in heel. ${ }^{21}$ Park et al. demonstrated that using footwear made of PLA (poly lactic acid resins) resulted in greater contact area and reduced peak pressure and maximum force in comparison with a regular control boot during treadmill walking. ${ }^{29}$ Moreover, Keijsers et al. demonstrated that individual characteristics like age, weight, height, foot width, foot length, contact time and gender are also having influencing effect on $\mathrm{PP}^{30}$

The second important observation of the present study was that the most prone affected region to injury identified as heel compared to other foot regions (Figure- 1-4). This finding is partly corroborated with the findings of Park et al. where it was found that peak pressure, maximum

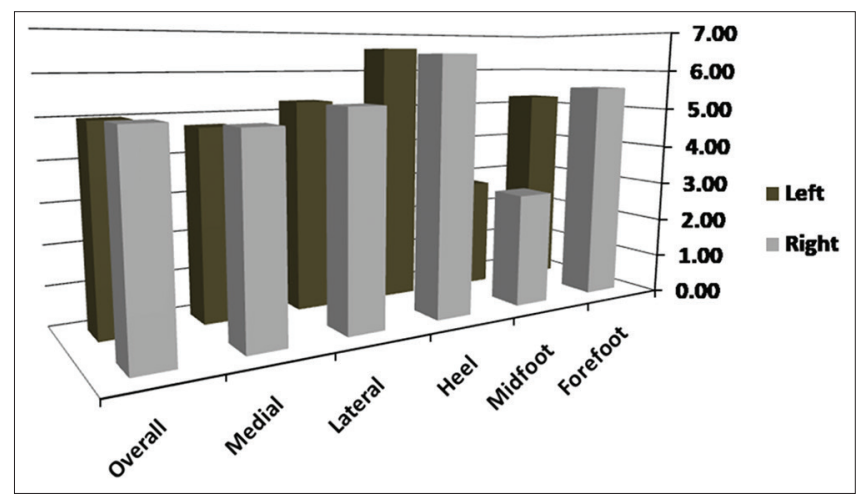

Figure 1: Graphical representation of plantar pressure of different foot regions in the right and left foot at $0 \%$ gradient with walking speed of $4 \mathrm{~km} / \mathrm{h}$ walking speed

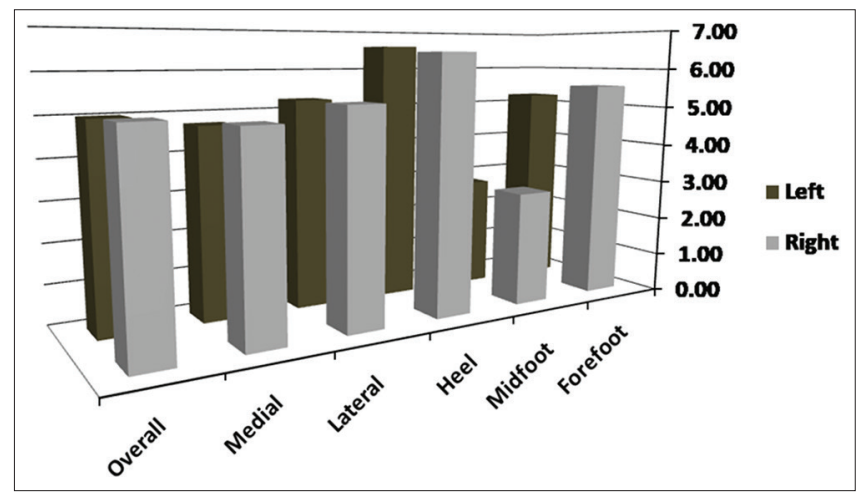

Figure 2: Graphical representation of plantar pressure of different foot regions in the right and left feet at $5 \%$ gradient with walking speed of $4 \mathrm{~km} / \mathrm{h}$ walking speed 
mean pressure and maximum force were lesser in mid-foot compared to forefoot and heel irrespective of shoe type. ${ }^{29}$ It was also found that PP at left heel region increased compared to right foot whereas $\mathrm{PP}$ in other regions of right foot was found higher than left. Rai et al. observed that $17 \%$ of the experimental population executed equal pressure on both feet, $7 \%$ showed greater pressure on left foot and $76 \%$ found higher load on the right foot. ${ }^{31}$ Hence it can be stated that impact of gradient on right foot was more than left foot and it may be due to the effect of dominancy of leg.

Another important factor was the way of presentation of plantar pressure. Majority of above mentioned studies ${ }^{18-21}$ analyzed only mean and peak pressure values of each trial whereas present study considered whole time frame of the trial and analyzed pressure time integral. It is the value of plantar pressure which seems to be more accurate as considering the relationship between plantar pressure and foot pain. A pressure time integral is the representative of magnitude of pressure as well as the rate at which pressure is loaded. ${ }^{32}$ The calculation is done as the sum of peak

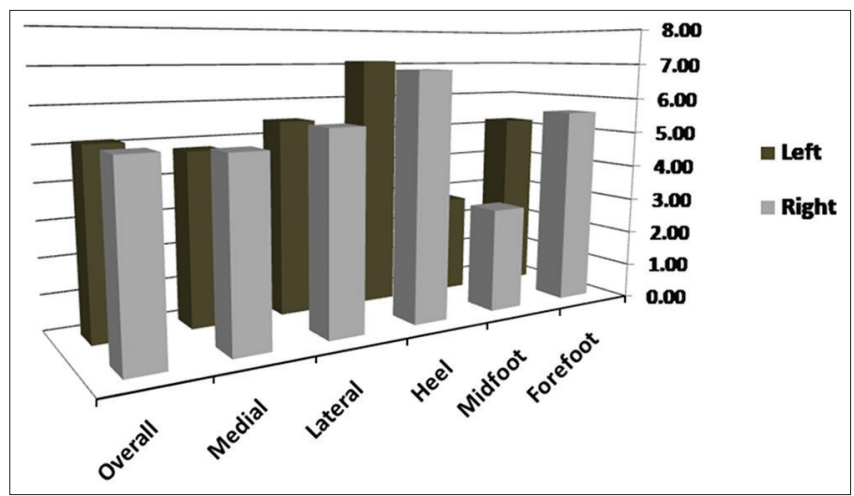

Figure 3: Graphical representation of plantar pressure of different foot regions in the right and left feet at $10 \%$ gradient with walking speed of $4 \mathrm{~km} / \mathrm{h}$ walking speed pressure in each frame of foot contact multiplied by the duration of foot contact. Higher pressure-time integrals recorded in our study were predominantly resulted from the increased duration of foot contact and peak pressure as demonstrated by Burns et al. ${ }^{33}$. Uphill walking induced fatigue in the legs resulted in higher pressure time integral which in turn alters normal gait dynamics of both feet. ${ }^{34,35}$

Different strength of correlation between overall PP and pressure at specific region of both feet were observed with the increase in gradient. As overall PP is a resultant measure of pressure at forefoot, mid-foot, medial, lateral, and heel, it was important to establish relation between overall PP and pressure at specific region with an approach of partial correlation. Left medial and lateral PP was found with a strong correlation with Overall PP across all gradients. In right foot, forefoot PP was strongly correlated with overall PP at 5\% gradient. Therefore, it can be postulated that increase in forefoot PP is an indicator of increased overall pressure. Similarly, at 10\% gradient overall PP was strongly correlated with heel, medial and lateral PP for both feet. Right heel PP at 10\% gradient showed highest correlation $(\mathrm{r}=1)$ with overall $\mathrm{PP}$ which depicted that right heel region was more susceptible than any other region of the foot contributing mostly for increase in overall PP with increased risk of injury at higher gradient.

\section{CONCLUSION}

This data will be considered as normal planter pressure value of adults at level and uphill gradients shod walking and may be utilized for prognosis of foot disorders and efficacy of treatment modalities of population comparable with studied individuals (for similar age, height and weight). Observations of the present study may be beneficial in

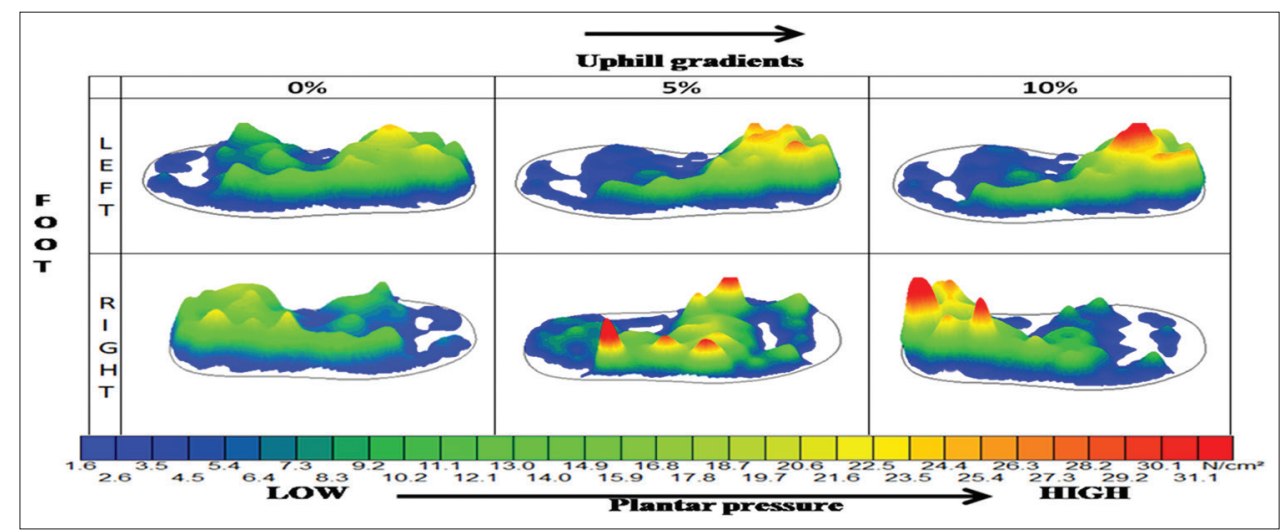

Figure 4: Pedobarographical presentation of plantar pressure of both feet, In left foot higher plantar pressure observed at heel region (visible as red area) in comparison with the other foot regions with increasing gradient. Same pattern of pressure distribution was also observed in right foot with increasing gradient. Pressure distribution in all regions with increasing gradient is higher in right foot than left foot. Exception was observed in $5 \%$ gradient where heel pressure is lesser in right foot in comparison with left foot 
conveying a practical knowledge towards the designing of various occupational/functional footwear with improved design features and advanced cushioning at foot bed for reducing the risk of injuries by minimizing planter pressure under adverse occupational environment.

\section{Limitations of study}

Present study was limited to the application of only two uphill gradients (5 and $10 \%$ ) at a constant speed $(4.0 \mathrm{~km} / \mathrm{hr})$, and male subjects. Therefore, future studies may be directed to inclusion of other uphill as well as downhill gradients, different walking speed, sex and age variation, effect of dominancy of leg, different footwear.

\section{ACKNOWLEDGEMENTS}

We would like to express our profound gratitude to Defence Research and Development Organization (DRDO) for funding and providing infrastructure for this study. Authors are extending their heartfelt thanks to the participants for sparing their precious time to participate in the study.

\section{FUNDING}

The project was funded by Defence Research and Development Organization, Ministry of Defence, India.

\section{ETHICS APPROVAL AND CONSENT TO PARTICIPATE}

This research was completed under the ethical approval of the Institutional ethics committee of DIPAS, DRDO.

\section{REFERENCES}

1. Abdul Razak AH, Zayegh A, Begg RK and Wahab Y. Foot plantar pressure measurement system: A review. Sensors. 2012; 12(7):9884-9912.

https://doi.org/10.3390/s120709884

2. Hennig EM, Staats $A$ and Rosenbaum D. Plantar pressure distribution patterns of young school children in comparison to adults. Foot \& ankle international. 1994; 15(1):35-40.

https://doi.org/10.1177/107110079401500107

3. Scott G, Menz HB and Newcombe L. Age-related differences in foot structure and function. Gait \& posture. 2007; 26(1):68-75.

https://doi.org/10.1016/j.gaitpost.2006.07.009

4. Queen RM, Abbey AN, Wiegerinck JI, Yoder JC and Nunley JA. Effect of shoe type on plantar pressure: a gender comparison. Gait \& posture. 2010; 31(1):18-22.

https://doi.org/10.1016/j.gaitpost.2009.08.235

5. Burns J, Crosbie J, Hunt A and Ouvrier R. The effect of pes cavus on foot pain and plantar pressure. Clinical Biomechanics. 2005; 20(9):877-882.

https://doi.org/10.1016/j.clinbiomech.2005.03.006
6. Rosenbaum D, Hautmann S, Gold M and Claes L. Effects of walking speed on plantar pressure patterns and hindfoot angular motion. Gait \& posture. 1994;2(3):191-197.

https://doi.org/10.1016/0966-6362(94)90007-8

7. Hennessy K, Burns J and Penkala S. Reducing plantar pressure in rheumatoid arthritis: a comparison of running versus off-the-shelf orthopaedic footwear. Clinical Biomechanics. 2007;22(8):917-923.

https://doi.org/10.1016/j.clinbiomech.2007.04.011

8. Kimmeskamp $S$ and Hennig EM. Heel to toe motion characteristics in Parkinson patients during free walking. Clinical biomechanics. 2001; 16(9):806-812.

https://doi.org/10.1016/S0268-0033(01)00069-9

9. Fawzy OA, Arafa Al, Wakeel MA and Kareem SH. Plantar pressure as a risk assessment tool for diabetic foot ulceration in egyptian patients with diabetes. Clinical Medicine Insights: Endocrinology and Diabetes. 2014; 7. https://doi.org/10.4137/CMED.S17088

10. Caselli A, Pham H, Giurini JM, Armstrong DG and Veves A. The forefoot-to-rearfoot plantar pressure ratio is increased in severe diabetic neuropathy and can predict foot ulceration. Diabetes care. 2002; 25(6):1066-1071.

https://doi.org/10.2337/diacare.25.6.1066

11. Lavery LA, Vela SA, Fleischli JG, Armstrong DG and Lavery DC. Reducing plantar pressure in the neuropathic foot: a comparison of footwear. Diabetes care. 1997; 20(11):1706-1710. https://doi.org/10.2337/diacare.20.11.1706

12. Mueller MJ. Application of plantar pressure assessment in footwear and insert design. Journal of orthopaedic \& sports physical therapy. 1999; 29(12):747-755.

https://doi.org/10.2519/jospt.1999.29.12.747

13. Praet SF and Louwerens JW. The influence of shoe design on plantar pressures in neuropathic feet. Diabetes care. 2003; 26(2):441-445.

https://doi.org/10.2337/diacare.26.2.441

14. Dobson JA, Riddiford-Harland DL, Bell AF and Steele JR. Effect of work boot type on work footwear habits, lower limb pain and perceptions of work boot fit and comfort in underground coal miners. Applied ergonomics. 2017; 60:146-153.

https://doi.org/10.1016/j.apergo.2016.11.008

15. Tokuhiro A, Nagashima $\mathrm{H}$ and Takechi $\mathrm{H}$. Electromyographic kinesiology of lower extremity muscles during slope walking. Archives of physical medicine and rehabilitation. 1985; 66(9):610.

16. Pivarnik J and Sherman N. Responses of aerobically fit men and women to uphill/downhill walking and slow jogging. Medicine \& Science in Sports \& Exercise. 1990; 22(1):127-130. https://doi.org/10.1249/00005768-199002000-00020

17. Sun J, Walters M, Svensson $N$ and Lloyd D. The influence of surface slope on human gait characteristics: a study of urban pedestrians walking on an inclined surface. Ergonomics. 1996; 39(4):677-692.

https://doi.org/10.1080/00140139608964489

18. Ho IJ, Hou YY, Yang CH, Wu WL, Chen SK and Guo LY. Comparison of plantar pressure distribution between different speed and incline during treadmill jogging. Journal of sports science \& medicine. 2010;9(1):154.

19. Grampp J, Willson J and Kernozek T. The plantar loading variations to uphill and downhill gradients during treadmill walking. Foot \& Ankle International. 2000;21(3):227-231. https://doi.org/10.1177/107110070002100308

20. Park SB, Lee SY, Kim SM, Hwang YJ and Yoo KY. A biomechanical 
research of foot pressure for lower extremity in gait wearing trail walking shoes. Journal of Foot and Ankle Research. 2014; Vol $7(1): 1-2$.

https://doi.org/10.1186/1757-1146-7-S1-A136

21. Sun $D, G u$ Y, Mei $Q$, Shao $Y$, Sun $J$ and Fernandez J. Effect of heel heights on female postural control during standing on a dynamic support surface with sinusoidal oscillations. Journal of Motor Behavior. 2017;49(3):281-287.

https://doi.org/10.1080/00222895.2016.1191423

22. Hamill $\mathrm{J}$ and Bensel CK. Biomechanical Analysis of Military Boots. Phase 1. Materials Testing of Military and Commercial Footwear. Massachusetts Univ AMherst Biomechanics Lab; 1992 Oct 1.

23. Hamill $\mathrm{J}$ and Bensel CK. Biomechanical analysis of military boots: Phase III. United States Army Technical Report Natick/ TR-96.013, 1996, 11:42.

24. Reis JP, Trone DW, Macera CA and Rauh MJ. Factors associated with discharge during marine corps basic training. Military Medicine. 2007; 172(9):936-941.

https://doi.org/10.7205/MILMED.172.9.936

25. Finestone A, Giladi M, Elad H, Salmon A, Mendelson S, Eldad A, et al. Prevention of stress fractures using custom biomechanical shoe orthoses. Clinical Orthopaedics and Related Research. 1999; 360:182-190.

https://doi.org/10.1097/00003086-199903000-00022

26. Hinz P, Henningsen A, Matthes G, Jäger B, Ekkernkamp A and Rosenbaum D. Analysis of pressure distribution below the metatarsals with different insoles in combat boots of the German Army for prevention of march fractures. Gait \& posture. 2008;27(3):535-538.

https://doi.org/10.1016/j.gaitpost.2007.06.005

27. Bovi G, Rabuffetti M, Mazzoleni P and Ferrarin M. A multiple-task gait analysis approach: kinematic, kinetic and EMG reference data for healthy young and adult subjects. Gait \& posture. 2011; 33(1):6-13. https://doi.org/10.1016/j.gaitpost.2010.08.009

28. Koopman B, van Asseldonk EH and van der Kooij H. Speeddependent reference joint trajectory generation for robotic gait support. Journal of biomechanics. 2014;47(6):1447-1458.

https://doi.org/10.1016/j.jbiomech.2014.01.037

29. Park SB, Lee KD, Kim DW, Yoo JH and Kim KH. Plantar pressure distribution during treadmill walking in comfort shoes with PLA (Poly Lactic Acid) resins. Journal of Foot and Ankle Research. 2014; 7(1):1-2.

https://doi.org/10.1186/1757-1146-7-S1-A123

30. Keijsers NL, Stolwijk NM and Louwerens JW. The effect of various subject characteristics on plantar pressure pattern. Journal of Foot and Ankle Research. 2014; 7(1):1-2 https://doi.org/10.1186/1757-1146-7-S1-A40

31. Rai DV, Aggarwal LM and Bahadur R. Plantar pressure changes in normal and pathological foot during bipedal standing. Indian J Orthop. 2006; 40(2):119. https://doi.org/10.4103/0019-5413.34455

32. Fuller EA. Computerised gait evaluation. Clinical biomechanics of lower limb. St. Louis: CV Mosby. 1996:179.

33. Burns J, Crosbie J, Ouvrier R and Hunt A. Effective orthotic therapy for the painful cavus foot: a randomized controlled trial. Journal of the American Podiatric Medical Association. 2006; 96(3):205-211.

https://doi.org/10.7547/0960205

34. Benedetti MG, Catani F, Ceccarelli F, Simoncini L, Giannini S and Leardini A. Gait analysis in pes cavus. Gait \& Posture. 1997; 2(5):169. https://doi.org/10.1016/S0966-6362(97)83405-4

35. Sabir MU and Lyttle DA. Pathogenesis of Charcot-MarieTooth disease. Gait analysis and electrophysiologic, genetic, histopathologic, and enzyme studies in a kinship. Clinical orthopaedics and related research. 1984; (184):223-235. https://doi.org/10.1097/00003086-198404000-00038

\section{Author's contributions:}

SS- Data collection, analyzed, reviewed the literature, interpreted results, manuscript preparation; DB- Study design, statistical analyzed, interpreted results, revision of manuscript; SC- Data collection, analyzed, reviewed the literature; BK- Critical revision of the manuscript, interpretation; MP- Concept generated, finalized study design, overall coordination and supervision of the study.

\section{Work attributed to:}

Defence Institute of Physiology and Allied Sciences and Defence Research and Development Organization.

Orcid ID:

Dr. Madhusudan Pal - (1) https://orcid.org/0000-0002-9657-5858

Source of support: Defence Research and Development Organization, Ministry of Defence, Govt of India, Conflict of Interest: There is no conflict of interest reported in this study. 